\title{
A Rare Case of Myocardial Infarction with Nonobstructive Coronary Arteries Due to Hereditary Thrombophilia
}

\author{
Ramesh Bala Arivazhagan ${ }^{1}$ Manokaran Chinnusamy ${ }^{1}$ Ashida Thulaseedharan Sarojadevi ${ }^{2}$ \\ Sathiyanarayanan Janakiraman ${ }^{1}$ \\ ${ }^{1}$ Department of General Medicine, Sri Manakula Vinayagar Medical \\ College and Hospital, Kalitheerthalkuppam, Madagadipet, \\ Pondicherry, India \\ 2Department of Cardiology, Sri Manakula Vinayagar Medical College \\ and Hospital, Kalitheerthalkuppam, Madagadipet, Pondicherry,

\begin{abstract}
Address for correspondence Manokaran Chinnusamy, MBBS, MD, Department of General Medicine, 9, Associate Professor Quarters, Sri Manakula Vinayagar Medical College and Hospital Campus, Kalitheerthalkuppam, Madagadipet, Pondicherry 605107, India
\end{abstract} \\ (e-mail: manokaran.smvmch@gmail.com).
} India

J Health Allied Sci ${ }^{\mathrm{NU}}: 2021 ; 11: 101-103$

\begin{abstract}
Keywords

- MINOCA

- thrombophilia

- protein C and protein

$S$ deficiency

- anticoagulants

- recurrence of events

The incidence of acute myocardial infarction with nonobstructive coronary arteries in young age less than 20 years in India due to hereditary thrombophilia is uncommon. Combined protein $\mathrm{S}$ and protein $\mathrm{C}$ deficiency has an increased tendency for coronary artery thrombosis in very young individuals. Acute myocardial infarction in young individuals has different risk factors profile, clinical presentation, and prognosis when compared with elderly population and hence incites the need for different approach in the management. Here we report a case of 17 -year-old boy who presented with acute inferior wall myocardial infarction with nonobstructive coronary arteries due to hereditary protein $\mathrm{C}$ and protein $\mathrm{S}$ deficiency.
\end{abstract}

\section{Introduction}

Coronary artery diseases are considered to be one of the leading causes of mortality and disability in adults worldwide. Acute myocardial infarction in very young patients less than 35 years of age is estimated to be less than $2 \%$. In India there is a rise in the number of young patients with myocardial infarction, where majority of people lack the conventional risk factors. ${ }^{1}$

Young adults with no evidence of atherosclerosis and no major risk factors should be evaluated for deficiency of major anticoagulant proteins especially protein $\mathrm{C}$ and protein $\mathrm{S}$. The patients with myocardial infarction should be started on lifelong systemic anticoagulants to prevent the recurrence of events.

\section{Case Report}

A previously healthy 17-year-old boy presented to the emergency department with complaints of recurrent vomiting

published online

December 30, 2020
DOI https://doi.org/

$10.1055 / \mathrm{s}-0040-1722427$ ISSN 2582-4287. and epigastric pain associated with palpitation and giddiness for 1 hour. He was conscious, oriented with normal Glasgow Coma Scale. His blood pressure was 100/60 mm Hg, heart rate of 88 per minute, saturation was $100 \%$ at room air. His cardiovascular clinical examination was found to be normal.

A standard 12 lead electrocardiogram (ECG) showed ST segment elevation of more than $2 \mathrm{~mm}$ in lead II, III, aVF suggestive of inferior wall myocardial infarction ( - Fig. 1) with no extension in right ventricular and posterior wall which was confirmed by taking right-sided and posterior ECG. Basic investigations were found to be normal. The two-dimensional (2D) echocardiogram showed an adequate LV function with mild hypokinesia of inferior wall. He was immediately thrombolyzed with injection Tenecteplase (recombinant tissue plasminogen activator), after thrombolysis he symptomatically improved with resolution of ST segment elevation indicating successful thrombolysis. CK-MB (creatine kinase myocardial band) was elevated, and troponin I was found to be positive.

(c) 2020. Nitte (Deemed to be University).

This is an open access article published by Thieme under the terms of the Creative Commons Attribution-NonDerivative-NonCommercial-License, permitting copying and reproduction so long as the original work is given appropriate credit. Contents may not be used for commercial purposes, or adapted, remixed, transformed or built upon. (https://creativecommons.org/licenses/by-nc-nd/4.0/).

Thieme Medical and Scientific Publishers Pvt. Ltd. A-12, 2nd Floor, Sector 2, Noida-201301 UP, India 
He underwent elective coronary angiography which showed normal epicardial coronaries ( - Fig. 2). Therefore, we sought to investigate the nonatherosclerotic cause of acute myocardial infarction in the young individual; evaluation of hypercoagulable risk profile was done. It revealed the deficiency of protein S, $30 \%$ and protein C, 59\%. We have evaluated the serum homocysteine levels and it was found to be $18.55 \mu \mathrm{mol} / \mathrm{L}$ (normal: 5.46 $16.2 \mu \mathrm{mol} / \mathrm{L}$ ). Hence a diagnosis of acute myocardial infarctions due to hereditary thrombophilia was made. Patient improved symptomatically and was started on oral anticoagulants. During the follow-up after 8 weeks, protein S (54\%) and protein C (52\%) levels were still low. The 2D echocardiogram did not reveal any regional wall motion abnormality and had normal LV function (-Fig. 3).

\section{Discussion}

Acute myocardial infarction in young individuals less than 20 years is very uncommon in India. ${ }^{2}$ Patients presenting with acute myocardial infarction in the absence

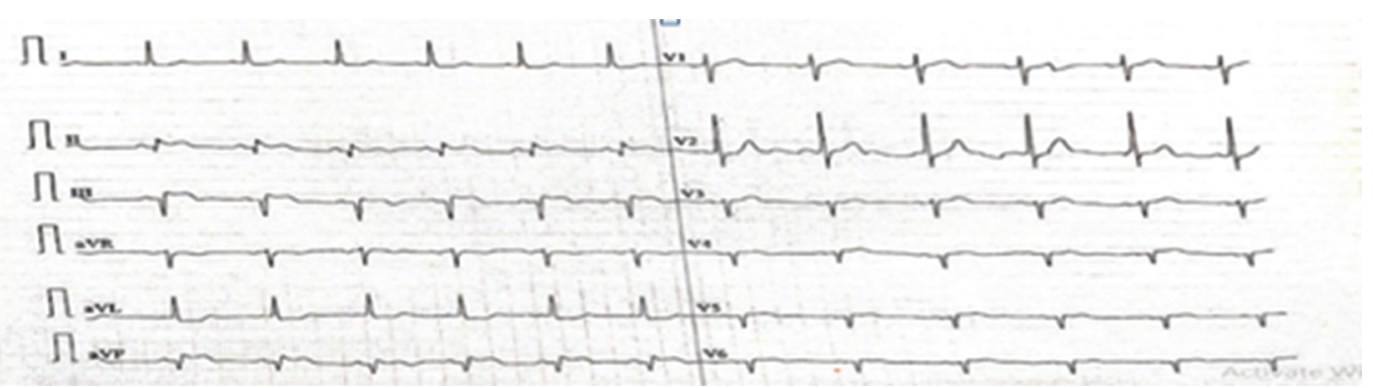

Fig. 1 ECG shows ST segment elevation >2 mm in lead II, lead III, and lead aVF, suggestive of IWMI. ECG, electrocardiogram; IWMI, inferior wall myocardial infarction.

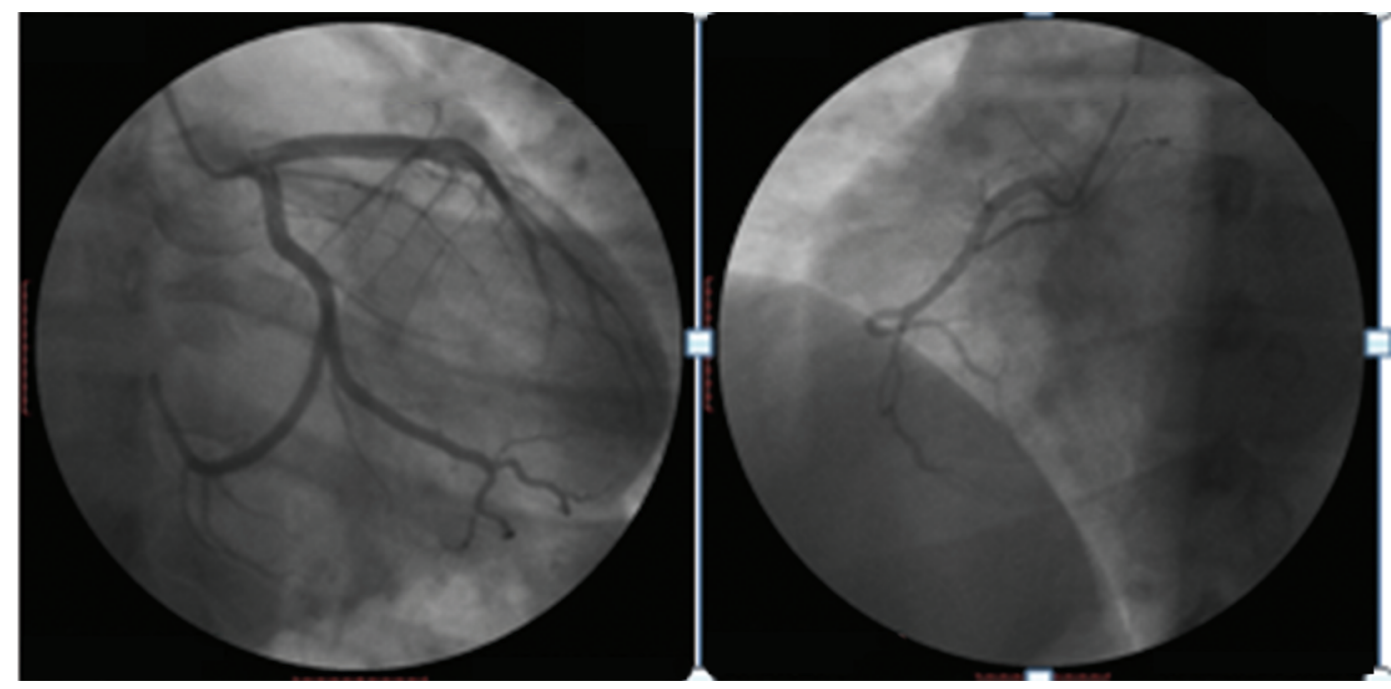

Fig. 2 Coronary angiogram showing normal epicardial coronaries with left dominant system.
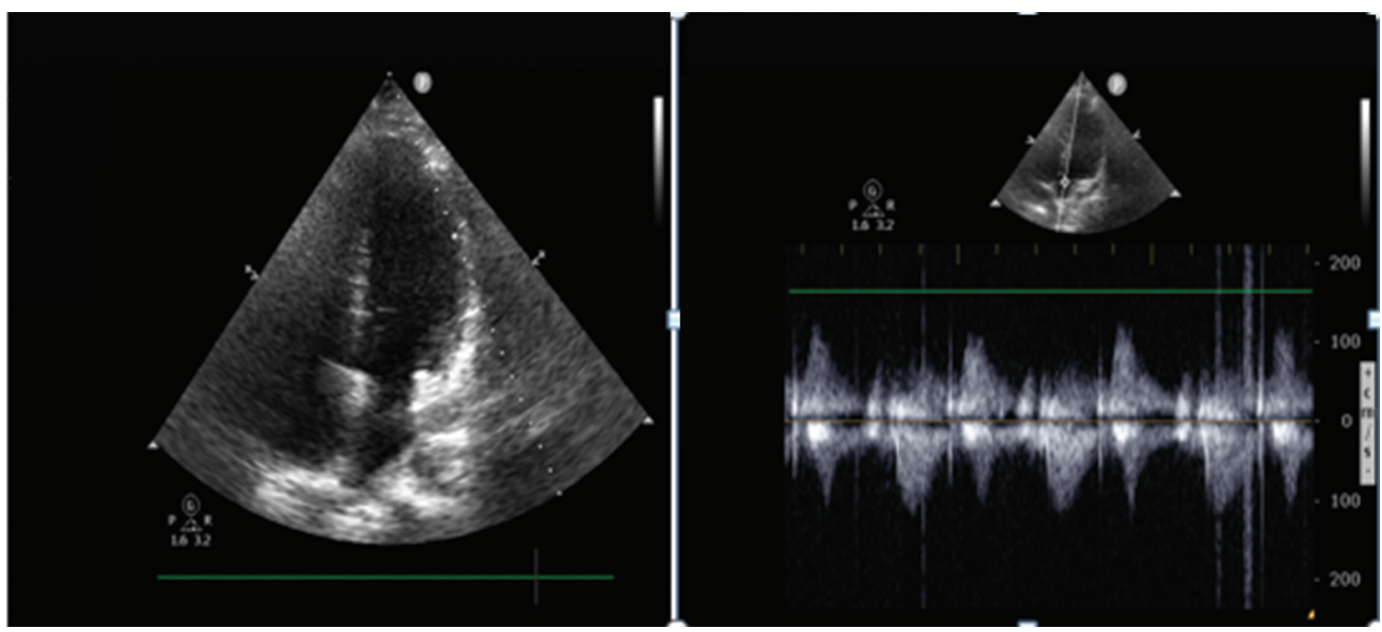

Fig. 3 On follow-up 2D echo four chamber view shows no regional abnormality, normal LV function. 2D, two-dimensional. 
of obstructive coronary artery disease is termed as myocardial infarction with nonobstructive coronary arteries (MINOCA). ${ }^{3}$

The prevalence of MINOCA is 1 to $4 \%$ when the definition is restricted to completely normal coronaries ( $0 \%$ stenosis ). ${ }^{4}$ Myocardial infarction in young adults can be broadly divided into two groups, those with angiographically normal coronary arteries and those with coronary artery disease of varying etiology. ${ }^{5}$ Myocardial infarction in young individuals with normal coronary arteries with no major risk factors, hypercoagulable state like hereditary thrombophilia has to be considered.

Based on the pathogenesis, myocardial infarction in young adults is divided into four groups (1) atheromatous coronary artery disease, (2) nonatheromatous coronary artery disease, (3) myocardial infarction related to substance misuse (cocaine), and (4) hypercoagulable state like in our case. ${ }^{6}$

Thrombophilia can be defined as an increased risk of thrombosis and it can be either hereditary or acquired. The hereditary causes are protein $C$ and protein S deficiency, antithrombin III, Factor V Leiden mutation, hyperhomocysteinemia, elevated levels of factor VIII, Von-Willebrand factor, and fibrinogen. The acquired causes are antiphospholipid antibody syndrome, cancer, and hyperhomocysteinemia due to nutritional deficiency. ${ }^{7}$ Protein $C$ is a vitamin K-dependent coagulation inhibitor that acts on factor V and factor VII, while protein S is a cofactor of activated protein $C$. Deficiency of either of these proteins causing arterial thrombosis is very rare. ${ }^{8}$

Deficiency of protein $\mathrm{C}$ and protein $\mathrm{S}$ predisposes an individual to an increased risk of thromboembolism. It may manifest as venous thromboembolism in the leg, pulmonary embolism, stroke, or Budd-Chiari syndrome. Protein C and protein $\mathrm{S}$ deficiency have been reported in disorders like nephritic syndrome, inflammatory bowel disease, human immunodeficiency virus, varicella, multiple myeloma, sepsis, etc. ${ }^{9}$ Although they more commonly manifest as venous thromboembolism, rarely they can present as arterial thrombosis in the ratio of $24: 1$ with fatal mortality.

\section{Conclusion}

Any young individual with myocardial infarction and normal coronary arteries without any major risk factors or hypercoagulable state has to be evaluated as a dictum.
The identification of hereditary thrombophilia disorders is necessary as it may affect the patient's offspring. Lifelong oral anticoagulants and antiplatelets is the recommended treatment of choice in this population to prevent the recurrence of events. ${ }^{10}$ The early diagnosis and treatment is necessary to prevent untoward cardiovascular morbidity and mortality in young patients.

\section{Conflict of Interest}

None declared.

\section{References}

1 Sinha SK, Krishna V, Thakur R, et al. Acute myocardial infarction in very young adults: a clinical presentation, risk factors, hospital outcome index, and their angiographic characteristics in North India-AMIYA Study. ARYA Atheroscler 2017;13(2):79-87

2 Brill IC, Brodeur MT, Oyama AA. Myocardial infarction in two sisters less than 20 years old. JAMA 1971;217(10):1345-1348

3 Pasupathy S, Rodgers S, Tavella R, McRae S, Beltrame JF. Risk of thrombosis in patients presenting with myocardial infarction with nonobstructive coronary arteries (MINOCA). TH Open 2018;2(2):e167-e172

4 Pasupathy S, Tavella R, McRae S, Beltrame JF. Myocardial infarction with non-obstructive coronary arteries-diagnosis and management. Eur Cardiol 2015;10(2):79-82

5 Osula S, Bell GM, Hornung RS. Acute myocardial infarction in young adults: causes and management. Postgrad Med J 2002;78(915):27-30

6 Egred M, Viswanathan G, Davis GK. Myocardial infarction in young adults. Postgrad Med J 2005;81(962):741-745

7 Mohanty D, Ghosh K, Khare A, Kulkarni B. Thrombophilia in coronary artery disease: a double jeopardy. Indian J Med Res 2004;120(1):13-23

8 Çakır O, Ayyildiz O, Oruc A, Eren N. A young adult with coronary artery and jugular vein thrombosis: a case report of combined protein $\mathrm{S}$ and protein $\mathrm{C}$ deficiency. Heart Vessels 2002;17(2):74-76

9 Tahir F, Majid Z, Majid B, Khan S. Acute myocardial infarction as an initial presentation of protein $C$ and protein $S$ deficiency followed by dilated cardiomyopathy in a young male. Cureus 2019;11(4):e4492

10 Osman I, Patel B, Koromia G, Movahed A. Unusual acute myocardial infarction in young male with hereditary protein $C$ and S deficiency. J Clin Image Case Rep. 2017;1(1):100010146 